\title{
Fachdidaktik and the Development of Generalised Subject Didactics in Germany
}

Helmut Johannes Vollmer

\section{(2) OpenEdition \\ 1 Journals}

\section{Electronic version}

URL: http://journals.openedition.org/educationdidactique/1861

DOI: 10.4000/educationdidactique.1861

ISSN: 2111-4838

Publisher

Presses universitaires de Rennes

\section{Printed version}

Date of publication: 30 July 2014

Number of pages: 23-34

ISSN: 1956-3485

\section{Electronic reference}

Helmut Johannes Vollmer, «Fachdidaktik and the Development of Generalised Subject Didactics in

Germany ", Éducation et didactique [Online], 8-1 | 2014, Online since 15 September 2016, connection on 01 May 2019. URL : http://journals.openedition.org/educationdidactique/1861 ; DOI : 10.4000/

educationdidactique.1861 


\section{FACHDIDAKTIK AND THE DEVELOPMENT OF A GENERALIZED SUBJECT DIDACTICS IN GERMANY}

Helmut Johannes Vollmer

Universität Osnabrück 
Helmut Johannes Vollmer

\section{INTRODUCTION : WHAT IS FACHDIDAKTIK ?}

The German term Didaktik, independent of its historical roots and shades of meaning, traditionally denominates the science of teaching and learning, relating to the formation of human beings and thus to any content or content-based skills inside and outside school. In this wide understanding, all places and institutions transferring knowledge or "teaching" consciously would have an underlying didactic dimension. Museums for art or history or for experiencing aspects of natural sciences, for example, as much as broadcasts on television featuring non-fictional topics would be included : they have a didactic purpose. Their goal is to inform, to sensitize or to convince different audiences about something important. They want to pass on (new) knowledge or to differentiate already existing knowledge, in whatever ways, but successfully so. Thus, goal-oriented planning, interaction and some kind of accountability are implied - all of them are core components of Didaktik. ${ }^{1}$

It is assumed that all learning is content-based, mediated through specific topics or problems, which are challenging. This requires looking deeper into the subject matter of goals, topics and tasks, the structures, categories and specific demands they imply or pose - and the effect of content on teaching and learning. All of these issues are treated within specific domains called Fachdidaktiken (in the plural). The term thus relates to the science and art of teaching and learning subject-specific content, skills and procedures inside and outside school (cf. Schneuwly 2011, Vollmer 2011).

"Subject didactics" (SDs) have well established themselves in Germany over the last 30-40 years. They mediate between the knowledge structures of related academic disciplines and selected aspects of this knowledge base to be taught and learned in school (namely within subjects, German : Fach) or beyond. The planning and managing of effective knowledge acquisition through successful teaching and classroom interactions can only partly be characterized in scientific terms - it has also an intuitive, creative and holistic side to it. This can differ from one subject to another as well as from one person to another, teachers and students alike, who jointly shape these concrete processes and the dynamics of classroom learning (as forms of institutionalized teacher/learner/content encounters). These interac- tive processes and their outcomes also have a general educational dimension beyond mere knowledge construction : they shape the individuals as life-long learners, as thinkers, as social actors, as citizens, as reflective practitioners in their future jobs and in their private lives, either explicitly or implicitly so. Thus the constellations of the persons involved, including background, attitudes or mental sets, are as important as the content itself for subject-specific learning outcomes and their relevance. Accordingly, the language of description, of analysis and of evaluation for these outcomes can vary considerably from person to person and subject to subject.

In a recent attempt to define the common core among the different school subjects and the subjectspecific didactics dealing with them, a group of German scholars (subject didacticians) set out to discover and describe the possible unifying forces among them in theoretical and functional terms without neglecting their differences. While striving for a shared understanding and definition of Fachdidaktik as a whole (in the singular), they also wanted to capture and acknowledge the remaining specificities of each single subject-related didactics at the same time. This could only be done through a joint effort among representatives from different subjects and thus from different schools of thinking. By studying in-depth the inner and outer reality of different forms of subject learning this led to two opposite, but complementary procedures : theoretical abstraction on the one hand and comparative research on the other hand (see Abraham, Bayrhuber, Frederking, Jank, Rothgangel $\&$ Vollmer, in preparation, but also below). In the following, the major steps towards establishing and defining a generalized Fachdidaktik (as an integrative new discipline) will be outlined. ${ }^{2}$

\section{DEVELOPMENT OF INDIVIDUAL SUBJECT DIDACTICS IN GERMANY SINCE THE 1970S}

In order to understand where a potential generalized Subject Didactics (in German : Allgemeine Fachdidaktik, in the singular) could be positioned within the system of sciences and how individual Fachdidaktiken (subject didactics in the plural) would relate to it as well as to one another, one has to reconstruct some important points of development during the last decades. This means, above all, to sketch some forms of cooperation among the 
different subject didactics as well as their attempts to identify and underline their common interests and goals. In particular, this relates to the development of a strong research orientation and a wide range of methodologies, but also to assuming responsibility for defining and evaluating the specific skills, competences and educational outcomes of subject teaching and learning.

Subject didactics in Germany experience an important phase of consolidation, each one of them separately and all of them together as a domain, mainly due to the acknowledgement of their importance for modern teacher education (after the first PISA shock in 2001 ; cf. Bayrhuber, Ralle, Reiss, Schön \& Vollmer 2004). This central role of subject didactics has largely to do with the history of curriculum theory and development in Germany and its pragmatic procedures as well as with the attempts to overcome the obvious deficits by strengthening empirical approaches to research, systematic data gathering and comprehensible theory building. Earlier the classical paradigm was to ask and postulate what the future needs and the true interests of individuals and society were (or would be). Based on these results appropriate goals would be identified and important content decisions made. It has to be acknowledged that such an approach at least brought the normative aspect of teaching to the forefront; it has led, for example, to the inclusion of ethical, value-based issues in biology or to focus on communicative competence within foreign language teaching and learning and thus on oral production. Also, a reflective dimension was introduced into all subjects, especially at the upper secondary level of schooling, preparing for a scientific mind and critical ways of thinking. At the same time, it also happened that the training of teachers at university focussed too much on the acquisition of academic knowledge in its first phase, while the second phase was merely geared to the more practical skills of teaching, as an art, rather than being an applied science. Subject didactics (SD) contributes to both phases, of course, through a creative reconstruction of what is indispensable and important to be learned and thus taught, and also through the provision of teaching examples, suggestions and manuals. But contrary to what was done in France, a scientific form of SDs could be institutionalized only in the first phase of teacher education (at the university level), at least to some extent (cf. Vollmer 2007).
It was not before the 1990s that an increasingly empirical orientation in studying the processes of teaching and learning within subject-specific contexts took over. Meanwhile a few research institutes for the Didaktik of certain subject areas or domains had been founded, of which the Institut für die Pädagogik der Naturwissenschaften (IPN) in Kiel was the most known and influential one and still is to this very day. Consequently, more and more cooperation with colleagues from psychology and the educational sciences developed, applying many of their analytical instruments and methods to basic research issues in the teaching and learning of subjects. Quantitative approaches gained in importance, yet the normative dimension of SD stayed always a constituent part of it, as much as the practical issues within the classroom : the first one shows in the necessity to justify the specific selection of subject-based as well as educational goals, the second one documents itself in the quality of different decision-making processes and how these can be identified and demonstrated, according to certain criteria.

As the empirical research-mindedness spread, different subject didactics formed networks for mutual support, especially in preparing successful research applications and in designing joint studies for observing and improving classroom practices. This was accompanied by supportive moves from the national funding agencies, which saw the enormous need for catching up with didactic research, and allowed for collective consultation and evaluation of packages of research projects. As a consequence, the formulation of high standards and explicit criteria for one's own research activities, for observing and improving classroom practices as well as for drawing conclusions from empirical studies in general increased in quality and precision. Accordingly, first publications appeared, with contributions from a number of subject didactics, illustrating the application of principles and the practices of research within the different disciplines (e.g. Bayrhuber, Finkbeiner, Spinner \& Zwergel 2000).

\section{FOUNDING OF THE "ASSOCIATION FOR FACHDIDAKTIK" AS A PLATFORM FOR ALL SUBJECT DIDACTICS}

Over the years of loose cooperation among the professional representatives from different subject 
didactics it became obvious that more coordination and greater cohesion was needed in the professional discourse and the political procedures for strengthening subject didactics as such. This was particularly true with respect to scientific self-presentation and equality of status, to research funding, to establishing professorial chairs (for each subject didactics in each university) and the development of a basic curriculum for Fachdidaktik (across subjects) within teacher education. For each of those issues a common platform had to be formulated with the goal of agreeing on joint positions and general lines of action. Based on the already existing networks among the different didactics, a formal agency was founded in 2001 for the representation of the common interests and perspectives, namely the institutionalization of a national "Association for Fachdidaktik" (in German : Gesellschaft für Fachdidaktik - GFD).

In the following, some of the elements leading to an increase in cooperation between the individual $\mathrm{SD}$ and consequently to the strengthening of the GFD as an integrative and unifying agency will be described. The chairmen of all individual member organizations, for example, meet on a regular basis, at least twice a year for two days each time. This is when joint decisions are prepared and taken. This is also where elections take place every two years. The business agenda can cover anything from planning the next topical conference or helping to rephrase the guidelines for research applications to structuring the qualification criteria for filling a post in subject didactics or writing a letter of protest to presidents of universities in case of urgent matters. In other words, each member agency can bring up almost any topic and present it to the body of elected representatives from the associations who will then decide how to deal with it.

In general, one can say that the GFD operates in a double way : both top-down (by offering theoretical orientation) and bottom-up, by taking account of the specifics of individual groups and organizations, but moving towards identifying the general common core among all of them, in practical as much as in conceptual terms. A good example of this is the joint development of a core curriculum for education and training in Fachdidaktik at university level, which could be applied to all the disciplines and programs of teacher training throughout Germany (cf. the relevant curricular modules, see Gesellschaft für Fachdidaktik 2005). It is important to state that a purely pragmatic procedure of aligning the interests of the 24+ member associations has not proven to be enough, it had to be complemented by a theoretically driven top-down approach which confronts the different individual subjects and subject didactics with a unifying system of categories and approaches which can be checked against their own use and validity. As an example one could refer to the extensive discourse on the need to define subject-specific competences in theoretical terms within differing models of naming, describing and evaluating them - as opposed to the mere identification of language competences as part of subject knowledge and skills (cf. Vollmer 2005). The former approach requires fundamental forms of re-thinking and new orientations in content-based cognitive research whereas the latter approach may be managed by observing classroom practice within and across subjects (see the recent publication on Sprache im Fach/ Language in the content classroom by Becker-Mrotzek, Schramm, Thürmann \& Vollmer 2013). Such double procedures (support of the immediate demands, yet confrontation with new conceptual challenges) seem to work well and are promising for the future in that they help to unfold the individual subject didactics while strengthening the cohesive links between them at the same time, bringing the general perspective into focus (cf. Bayrhuber et al. 2011).

Other procedures applied at the membership meetings also work into the same direction : e.g. reporting about the academic activities and discussions of each didactic association (so that others are informed and can relate) or taking time for casual group work in clarifying certain incidences and issues, with reports back to the plenary. In this manner, the GFD as a provisional form of institutionalisation for general subject didactics makes sure that the decision-making processes remain transparent and the whole is in the interest and control of the individual associations as "members". This also requires a constant feedback between the governing board of the GFD and the different subject didactic organisations. As an incentive, the association can afford to give awards on a regular basis for outstanding performances in certain areas of subject didactics - or for lifetime contributions, as it were.

In addition to plenary meetings (with all members present) there are also ad-hoc groups constituted for preparing recommendations on certain issues (like establishing funding criteria for didactic research - as 
opposed to regular scientific research - or scanning the existing subject-didactic journals in terms of their policies of evaluation (e.g. double blind peerreviews), their productivity or international acceptability. During our bi-annual thematic conferences a large proportion of discussion time is devoted to the identification of the links between different research approaches and different subject-specific views on one and the same topic and thus of a possible common core behind the multitude of data sets and models, striving for valid categorizations of formats, types and structures. ${ }^{3}$

Overall, there are mildly competitive structures embedded into the agenda of the GFD : for example, applications for presenting a research paper on one of the bi-annual thematic conferences used to go through the respective membership organisations (two applications per association) - for the conference in October 2013 on the role of Tasks in subject teaching and learning, some form of open self-application was practised for the first time, requiring a longer and a more intense process of peer reviewing and decision-making about who is going to be included into the program. Also, a model of parallel sessions will be experimented with for the first time so to cover the topic within two conference days and give roughly 30 more or less young didactic researchers a chance to present part of their work including theoretical framework, design of the study and discussion of findings. Stimulating discourse among the disciplines is one of the decisive goals, as it was the case during a special conference on Video-based research on competences (Riegel \& Macha 2013) and will also be the case within a cooperative project between two research groups in different places (Dortmund and Oldenburg) on Developmental Classroom Design (Komorek \& Prediger 2013). ${ }^{4}$

\section{TOWARDS A GENERALIZED SUbJECT DIDACTICS}

\section{Searching for a common core between individual subject didactics}

Within school as an institution the processes of teaching and learning are normally organized into units of study and performance called school subjects. One the one hand, these can be more or less widely defined as reflecting/dealing with particular domains of reality, with some overlap between them - like mathematics, music or history (the latter is sometimes further subdivided into world history, national history or regional history). On the other hand, subjects like biology, chemistry and physics are sometimes integrated into science education as a domain or "subject" of its own. All school subjects relate to one or more academic fields of study at the research level - but not directly, because these research fields, as fundamental and dynamic as they are, follow their own rules and agenda. It is only when they have been processed and structured and transformed accordingly that they become academic disciplines for the purpose of being taught and learned at universities or institutions of higher education in general. So the academic disciplines as one set of reference system for subject didactics already represent transformed units of knowledge and study which are then further mediated through reconstructive and selective didactic processes for teaching and learning at school. In German, this close link between the didacticized form of research areas as academic disciplines and the didactic efforts for creating teachable subject areas in school is expressed through the ambivalent use of the term Fach in all three cases (we talk about Fachwissenschaft, Fachdidaktik, Schulfach).

But SD equally draws on insights and results from the different educational sciences, which are usually not subject matter oriented. On the contrary, they focus mainly on general issues of learning and education, on the effects of institutional as much as of personal background variables, for example, or on the description of general psychological processes in the interaction between teachers and learners striving for specific goals etc. In a traditional view, therefore, any individual SD has to mediate between these two systems of reference (academic disciplines and educational sciences), oscillating between them, drawing on them, participating partly in both, yet being independent in following its own research agenda, research methods and application of its results for teaching. In particular, any Fachdidaktik has to re-analyze and select the right content for teaching and consider how best to teach this content given specific conditions, knowing the institutional setting and its effects, knowing the level of prior knowledge of learners, their mental and emotional conditions and their necessary role as active participants in the teaching/learning encounters. This task of reconstructing and modeling teachable content (both terms are used in different subject didactics) 
is at the heart of all didactic activities : it implies processes of evaluation, of selection, sometimes of fundamental reconceptualization and certainly of adaptation for specific groups of learners or institutional conditions. In some cases SD even has to generate scientific knowledge itself : this is the case when an academic discipline does not deal (enough) with certain areas or issues although they seem important for systematic learning from a didactic point of view. All these aspects have a normative side to them as much as they can be empirically studied (at least in most part) and be understood within appropriate didactic theories.

What is important to be added here is the fact that teaching and learning a subject is much more than acquiring knowledge of or within that subject. The majority of subject didacticians would agree that this process is one of co-construction in meaning-making and that it should be studied as such. Yet there is no consensus (not even in parts of the overall German community) on a specific didactic theory which would allow for a rational analysis and design of planning and teaching moves (all the way down to the micro level). On the other hand, it is largely believed that subject matter learning always implies the acquisition of transferable skills and categories to be used in other contexts of the same subjects or in another subject altogether; also, that subject learning leads to the development of general educational values, skills and competencies (like precision, openness, rationality, language awareness, or evidence-based thinking). In other words, we can or could identify a specific set of additional cross-curricular (non subject-specific) goals and competences involved in or triggered by school learning. This insight will be used later for comparing subjects (see 4.3).

\section{The three columns of Allgemeine Fachdidaktik integrated}

So far we have identified in a top-down way three different theoretical lines of thinking and research as part of an integrated Fachdidaktik, namely (1) the empirical study of basic teaching and learning principles as a result of concrete analysis and comparison, (2) the conceptual and terminological reconstruction or modelling of disciplinary content and its adaptation/mediation for teaching purposes and finally (3) the study of knowledge acquisition through subject-specific teaching/learning activities and of classroom interactions in detail. In viewing these three tasks as fields of professional activities, a generalized SD makes use of the insights and research results of many different fields of study - insights from academic reference disciplines as much as from the educational and social sciences concerning the learning individuals and institutionalized forms of teaching. In particular, it integrates the results of studies in at least six different areas of research or fields of concern which are somewhat overlapping, namely 1 . subject-related self-concepts of teachers and students, 2. subject-specific content and methods of epistemology, 3. subject-specific processes of teaching and learning, 4. subject-based interactions, 5. subject-specific competences, 6 . development of subject-related education or Bildung.

In other words, all three strands of scientific activities relate to one another, but they are integrated once more into a basic function in which different aspects of research and classroom design emerge into a transdisciplinary perspective. This is clearly a strong and marked quality of Fachdidaktik, as a matter of fact of all Fachdidaktiken (pl.) and thus of a GSD, to be multi-faceted and theoretically encompassing : Fachdidaktik participates in a variety of research strands, yet it adapts, qualifies and integrates them in its own independent way, according to its own principles and the specific (didactic) research question at hand. As to the theories and methodologies drawn upon, some important points of reference have already been identified within the research community, others have to be worked out more specifically. Among the formats of subject-based research one can distinguish at least between descriptive and analytical research, experimental research, implementation research, action research, design and development research, test and evaluation research or research on short-term or long-term effects (see Bayrhuber et al. 2012 and footnote 3).

A generalized SD, therefore, can be characterized as a transdisciplinary science with a function of orientation for the whole field of institutionalized education as much as for the different individual SDs. It thus defines the space for subject-related pedagogical action within institutional settings in more theoretical and generalized terms, on a metalevel so to speak, relating more clearly the different areas, functions and goals of didactic research and action to one another. By taking such a meta-theo- 
retical stance, a GSD can also help to develop a framework for comparing the products and processes of the individual subject didactics and thus for bringing out the common underlying ground in defining the core insights and knowledge among all subjectspecific parts and fields of study. In building up such a framework for comparison we can distinguish between three aspects or layers of learning associated with each subject, namely that of a) learning a subject (or in a subject), that of b) learning alongside with a subject and that of c) learning through a subject (see below). The latter aspect requires the development of a subject-based theory of education or Bildung, including the identification of a number of basic anthropological and socio-cultural dimensions which would be able to reflect and model the educational potential of the different subject-related teaching and learning processes and their outcomes in particular.

\section{A bottom-up approach of comparing different subject didactics}

The complementary movement of comparing individual subject didactics as to their self-understanding and their self-claimed outcomes gives us another opportunity to arrive at a possible common core among all subjects as much as to identify their specifics and general differences. The procedure followed here is one of description and of classification of any specifics (in terms of teaching outcomes, either planned or real) on a number of levels, before processing them for generalization and comparison on a more abstract categorical level. The first level of this bottom-up procedure relates to what might be considered the normal learning goals or outcomes within any one specific subject (characterized as learning of a subject or within a subject). This level reflects the shared goals of all or most didacticians of a particular subject in terms of the basic elements or structures of knowledge, of competences strived for or skills to be acquired. For the subject History, for example, this could comprise factual knowledge about the Who, How and When as well as the ability to relate historical incidents to one another or to be able to read a historical map.

The second level of this model relates to competences and skills which have been acquired within a specific subject matter context, but which are trans- ferable to other contexts within the same subject or which can be applied to new learning incidents outside the first subject. Potential candidates for such competences are procedural ones (like the ability to read between the lines or to interpret a graph or a text along certain criteria) and abilities of becoming aware of something, or reflect about implications of something or to look for similar or analogous structures of something (like in grammar or in music and art). Competences of this type are not acquired separately from the ones on the first level, but rather simultaneously; they are and remain available after a learning incident is over ; they form the basis of a cross-curricular pattern of skills and qualifications.

The third level of subject learning finally implies educational processes and results which can only be strived for, but not guaranteed for any student. These outcomes relate to the underlying potentials of "Bildung" which are inherent in subject-specific knowledge, procedures and competence aims and which can be captured only within or through a theoretical framework as outlined below. This framework tries to define the most relevant educational dimensions which might be involved in subject-specific teaching and learning - independent of whether they are made explicit or not. These dimensions can be characterized as anthropological on the one hand and socio-cultural on the other hand. They describe what learning a specific subject (or dealing with a concrete issue/topic) could or should lead to in terms of individuation, personality development, perception and mastery of the world and qualification as a socio-cultural being, as a participating democratic citizen. Thus we can distinguish at least between the following aspects :

\section{Anthropological dimensions}

1. Perception, orientation (ability to perceive and distinguish)

2. Experience (ability to open and process accordingly, including aesthetic experience)

3. Insight, awareness, cognition (understanding, constructing meaning)

4. Identity formation (defining and interpreting oneself and the world)

5. Ability to act

6. Responsibility, empathy 


\section{Socio-cultural dimensions}

7. Pursuit of happiness, mastery of life

8. Ability to work, to follow a profession, to create

9. Scientific mindedness

10. Discourse ability (communicative competence)

11. Participation as a citizen, in society, in social events

12. Cultural praxis.

These developmental dimensions qualifying the third level are provisional for the time being ; they will be spelt out in more detail at another place (see Abraham et al., in preparation). They are implied in all learning, but in concrete subject-based learning in particular. They build themselves up in close connection with level 1 and 2 - they are just another (additional) quality embedded in or attached to subject matter learning: whether they unfold and how cannot always be observed on a smaller time scale, e.g. within the immediate classroom. And certainly the learning individuals have to be involved in the evaluation of each dimension.

To sum up, the three levels of subject learning can be distinguished as follows :

1. Learning OF or WITHIN a subject (knowledge, skills, subject-specific competences). This means the reconstruction of content and practices that are specific to a subject.

2. Learning alongside WITH a subject (transferable skills and competences). This means identifying and using what is generalizable and applicable in other contexts,based on 1 .

3. Learning THROUGH a subject (long-range educational results, Bildung). This means the construction of the anthropological and social self while dealing with a subject or subject-specific problem/topic.

These distinctions allow us to describe the different outcomes of subject-based learning processes and their effects in terms of educational impact. At the same time, they allow us to develop categories and criteria for identifying the commonalities and differences between subjects and highlight their specifics in each case. Especially through the introduction of level three, it seems possible to evaluate the contributions of different subjects and their topical components for the overall formation of the learners in terms of individual, mental, social as well as cultural development. In turn, this gives us access to the core of all subject learning and how the different subjects in school as well as the related subject didactics correspond to one another and to the overall goals of initiating and qualifying the younger generations for life, for the workplace, as well as for democratic citizenship and social participation as a whole.

\section{Relationship between GSD and individual subject didactics}

Thus, GSD is primarily a construct for the time being which results from identifying a common core between all of the SDs as some sort of meta-theory and from comparing individual subject didactics under certain categories. General subject didactics as a theoretical concept cannot replace any single subject-based didactics or any domain- specific didactics. It can only partly comprise them, but can certainly lay the theoretical ground for their existence and their self-definition. And it can raise certain professional issues and problems of general interest, confronting the individual subject didactics with them and striving for an integrative view or a certain harmonization. It is not clear yet whether it makes sense to define GSD as a discipline of its own, to be established within the academic landscape. But certainly one can imagine GSD as some sort of transdisciplinary platform functioning as a long-term system of reference for all the individual subject didactics which could be strengthened or weakened over time, depending on the (theoretical) interests and the consensus among the individual subject associations. We do not have a complete overlap between the GFD and individual member associations ; rather the relationship is to be seen as dynamic and changing from one topic to another, with a tendency towards higher degrees of unification over time, however. But the GFD as a potential promoter of a GSD still remains an instrument in the hands of the individual didactic associations, at least so far.

\section{ADVANTAGES OF HAVING A CONSTRUCT AND A PLATFORM FOR GSD}

The advantages of having a common agency and representative of GSD are obvious. In the following we will summarize some of them. 


\section{On the conceptual/theoretical level}

1. We need a meta-theory of subject-based education or Bildung in order to define the role of subject didactics in general and that of individual subject-related didactics in particular.

2. We need appropriate concepts and valid criteria for relating and comparing the standards, goals and achievements of the different subject-specific didactics with one another.

3. In particular, we need a system of references in order to check the outcomes of the central transformational processes between the respective disciplinary knowledge base and feasible teaching/learning goals within school subjects.

4. A generalized view on subject didactics can better focus on the whole of Bildung within a theory of knowledge and knowledge use and thus assess the contribution of each school subject and their components.

\section{On the institutional level}

5. A generalized approach to subject didactics can better identify the basic challenges of schooling and teaching, affecting the different domains and subject didactics in a differentiated way.

6. It can validly represent the interests and contributions of subject didactics as a whole, e.g. in curriculum development, in the distribution of time and other resources, in the coordination of research agendas and evaluation approaches.

7. It is in a position to follow strategies for securing quality education through the teaching of the different subjects, for developing cross-curricular perspectives and supervising whole-school policies (e.g. for autonomous learning, for inclusion of vulnerable groups of learners, for language development as an integral part of subject learning etc.).

8. An agency for general subject didactics can better resist fragmentation and isolation in universities and colleges and can thus help secure the unity and quality of teacher education for all (e.g. by recommending the self-organization of all subject didacticians in one institution, by supporting the founding of centers for teacher training, by coordinating research activities).

\section{On the level of communication and discourse}

9. An agency for general subject didactics has to bring the individual associations and members within subject-specific didactics into professional contact and foster exchange and communication among them as far as possible.

10. Such an agency also has the task to stimulate and challenge the individual subject didactics (again and again), to request participation and positioning and thus work towards building up communalities as a long-range process.

11. In this perspective it can and should also secure communication among all didactics, especially among general subject didactics and general didactics as part of the educational sciences.

12. Finally, it could organize the didactic discourse among the sciences themselves (e.g. concerning their social value), among the academic disciplines and society as well as among school and society (e.g. about (minimal) educational goals and their realization). In this way the system of Fachdidaktik would become strengthened and perceived as one of the most important basic sciences of our times responsible for the mediation of knowledge, skills and democratic attitudes to all.

We are dealing here with an enormously important, wide and rich field of research, for which no independent scientific discipline is responsible so far. But this might slowly change over the years: we are in the process of identifying and describing a common object of study and theory building (see above) with specialized concepts, notions, and research methods ; we have initiated the development of discipline-specific networks, we have started to institutionalize the work through the creation of a formal agency and last, but not least, we are seeing to it that young researchers are qualified and equally socialized within transdisciplinary modes of thinking and exchanging - in addition to their specific major anchoring in one individual subject didactics. These are all indicators that a new "discipline" might come into existence : Generalized Subject Didactics. 
It remains to be seen in how far this newly emerging meta-discipline can already be characterized through its own separate field of study and be described convincingly in common theoretical terms. The fact, however, that Fachdidaktik is more and more perceived and addressed in the singular even by the outside, shows the developing state of affairs (e.g. Tenorth 2012, Terhart 2009, 2011). Independent from this general perspective, the individual subject didactics themselves (more than 20 member associations within the GFD) have initiated many relevant activities and produced many research results of their own all of which are well documented, but cannot be dealt with here (see the links under www.fachdidaktik.org).

There is an impressive increase in didactic knowledge and subject-related problem consciousness. In spite of the fact that more and more German didacticians cooperate with one another and/ or with educational psychologists on central issues of teaching and learning in specific subject matter areas and get well funded, there is still a lack of cohesion in design and approach among the different research groups, not to mention the diversity of research questions themselves. An overall agenda cannot be discerned so far - the young researchers simply do not keep to any non-existent framework. One possible way to support such a development towards more integration or unification would be through structuring programs of research and financial support accordingly, e.g. linked to the study of elements within a generalized subject didactics.

Nevertheless, research-mindedness has become a distinctive feature in the self-definition of subject didactics, with a marked quality of research in general (some criticism in this direction is often unjustified). As a matter of fact, experience in relevant subject didactic research is an unconditional prerequisite in applying for a professorship nowadays. While smallscale research by dissertation students, for example, normally operates within a qualitative framework/ design, larger projects apply multivariate methods of a quantifying nature. One consequence of this latter research orientation (mainly supported by funding agencies) is a certain danger of losing contact with everyday teaching practices within concrete subjects and with the professional knowledge already present and embedded in these forms of pedagogical action. We therefore have to bring the "wisdom" of the teachers, the existing, but often tacit knowledge of the (reflective) practitioners stronger into play again within research as an invaluable source of additional information. Each subject teacher has to mediate successfully on a daily basis between content and institutional demands (object side) and personal constellations (subject side) ; research should therefore draw upon the unmatched experiential basis. Nevertheless, subject didactics also have to insist on their genuine scope of research methods and further develop it, including design-based research approaches which include the active participation of teachers in developing and trying out new methods or approaches (cf. Prediger \& Link 2012, for example).

\section{SUMMARY}

In summarizing, one has to state that a generalized Fachdidaktik is under construction in Germany : it is seen as a theoretical and educational necessity, as a big step forward in the explicit definition and exchange about what SD is in its core, as a scientific field for securing the education of future generations on a high level of knowledge, expertise and professionalism, with systematic exchanges about it.

In spite of the great advances made during the last two decades towards developing a more generalized agency and, as a consequence, towards a theoretical base for a generalized subject didactics, the movement is far from having reached its goal - the establishment of a new scientific discipline. But its specific role and nature already becomes somewhat more visible in theoretical and practical terms.

Individual subject didactics have consolidated themselves enormously during the last years, each one differently and at different paces. This relates to the number of professorships (permanent posts), to the role in teaching and in academic self-administration, but also to research and the amount of funding received. But above all subject didactics has clearly assumed the active, defining role in all teacher education.

Nevertheless, the tensions known remain : those between theory and practice, those between a disciplinary knowledge base and what is considered to be teachable or worth teaching, those between the learning processes intended and the ones actually taking place. The very existence of a national association promoting a more generalized form of SD makes all 
these insights tangible and transparent, but above all accessible to the professional discourse among the member organizations. The GFD has already proven to be an appropriate platform for the development of unifying concepts relating to subject-specific research and classroom practice, for theoretical clarification and for joint institutional and political action towards establishing subject didactics as the conceptual centre of a modern teacher education at university level. Only they are in a position to balance the otherwise overwhelming dominance of the academic disciplines and their claims. SDs, but above all GSD, are guarantees of a sound professional socialization of future subject teachers, right from the start and throughout their careers.

\section{NOTES}

1. In the case of museums, however, the learners are visitors who come on their own will - different from schools which are defined as compulsory institutions by societies. This definitely has an influence on the kind of didactics necessary or appropriate.

2. Part of the thoughts expressed here has been formulated in French in a similar way; see Vollmer 2013. I am indebted to my colleagues U. Abraham, H. Bayrhuber, V. Frederking, W. Jank \& M. Rothgangel with whom I have the privilege of developing the concept of a generalized Fachdidaktik in Germany.

3. In this context, two standing committees have been operating within the recent past which will publish their results within our own well-established publication series "Fachdidaktische Forschungen": one of them on the Extension of Research Formats in Subject Didactics, the other one, as already mentioned, on the development of a Allgemeine Fachdidaktik (Towards Developing a Generalized Subject Didactics).

4. It might be added here that the typical background of people applying for or working in subject didactics in Germany is slowly changing; the younger ones clearly are expected to have a double qualification as an experienced teacher (normally three to five years of teaching within that subject) and as a didactic researcher nowadays. In other words, it is not enough to be rooted in the academic disciplines at university, although some colleagues manage to move from a disciplinary career into subject didactics. The same is true for teacher educators from the few teacher colleges left in Germany and from the institutions of the so-called second (practical) phase of teacher training (head teachers, principals etc.): there is hardly any larger transition into the academic teaching of subject didactics on their part, as it used to be the case in the earlier Fachdidaktik traditions. This "separation" is somewhat unfortunate and reflects to a certain extent a misconception of the difference between theory and practice (subject didactics is both "practice" and theory of practice!). On the other hand, it cannot be denied that subject didactics as independent disciplines can only gain or keep their appropriate status as a science within the competitive academic structures of a university by insisting on quality research, on equal budgeting/funding and the adequate training/ recruiting of its own younger staff. 


\section{RÉFÉRENCES}

,Abraham, U.,Bayrhuber, H.,Frederking, V.,Jank, W.,Ro thgangel, M. \& Vollmer, H. J. (in preparation). Auf dem Wege zu einer Allgemeinen Fachdidaktik. Münster : Waxmann.

Bayrhuber, H.,Finkbeiner, C.,Spinner, C. \& Zwergel, H.A. (eds.) (2000). Lehr-/Lernforschung in den Fachdidaktiken. Innsbruck : StudienVerlag. (Forschungen zur Fachdidaktik Bd. 1).

Bayrhuber, H.,Ralle. B.,Reiss, K.,Schön, L.-H. \& Vollmer, H. J. (eds.) (2004). Konsequenzen aus PISA. Perspektiven der Fachdidaktiken. Innsbruck: StudienVerlag. (Forschungen zur Fachdidaktik Bd. 6).

Bayrhuber, H. et al. (eds.) (2011). Zur empirischen Fundierung der Fachdidaktiken. Münster : Waxmann. (Fachdidaktische Forschungen Bd. 1).

Bayrhuber, H. et al. (eds.) (2012). Formate Fachdidaktischer Forschung. Empirische Projekte - Historische Analysen - Theoretische Grundlegungen. Münster : Waxmann. (Fachdidaktische Forschungen Bd. 2).

Becker-Mrotzek, M., Schramm, K., Thürmann, E. \& Vollmer, H. J. (eds.) (2013). Sprache im Fach. Sprachlichkeit und fachliches Lernen. Münster : Waxmann. (Fachdidaktische Forschungen Bd. 3).

Gesellschaft für Fachdidaktik (GFD) (2005). Kerncurriculum Fachdidaktik. Orientierungsrahmen für alle Fachdidaktiken. (Bearb. v. H. Bayrhuber \& H. J. Vollmer ; to be consulted under http://www.fachdidaktik.org).

Komorek, M. \& Prediger, S. (eds.). Der lange Weg zum Unterrichtsdesign. Zur Begründung und Umsetzung fachdidaktischer Forschungs- und Entwicklungsprogramme. Münster : Waxmann. (Fachdidaktische Forschungen Bd. 5).

Prediger, S. \& Link, M. (2012). Fachdidaktische Entwicklungsforschung - ein lernprozessfokussierendes Forschungsprogramm mit Verschränkung fachdidaktischer Arbeitsbereiche. In H. Bayrhuber et al. (eds.) ; Formate Fachdidaktischer Forschung (p. 29-45). Münster : Waxmann.
Riegel, U. \& Macha, K. (Hg.) (2013). Videobasierte Kompetenzforschung in den Fachdidaktiken. Münster : Waxmann. (Fachdidaktische Forschungen Bd. 4).

Schneuwly. B. (2011). Subject didactics - An academic field related to the teacher profession and teacher education. In : B. Hudson, B. \& M. A. (eds.), Beyond Fragmentation. Didactics, learning and teaching in Europe (pp. 275-286). Leverkusen : Budrich.

Tenorth, H.-E. (2012). Forschungsfragen und Reflexionsprobleme - zur Logik fachdidaktischer Analysen. In H. Bayrhuber, H. et al. (eds.), Formate Fachdidaktischer Forschung (pp. 11-27). Münster: Waxmann.

Terhart, E. (2009). Didaktik. Eine Einführung. Stuttgart : Reclam.

Terhart, E. (2011). Zur Situation der Fachdidaktiken aus der Sicht der Erziehungswissenschaft : konzeptionelle Probleme, institutionelle Bedingungen, notwendige Perspektiven. In H. Bayrhuber et al. (Hg.), Empirische Fundierung in den Fachdidaktiken (pp. 241-256). Münster : Waxmann.

Vollmer, H. J. (Coord.) (2005). Kompetenzen und Bildungsstandards - Beiträge der Fachdidaktiken. Workshop of the Gesellschaft für Fachdidaktik in Salzau, 24.-25.11.2005. (To be consulted under http://www. fachdidaktik.org/Veröffentlichungen).

Vollmer, H. J. (2007). Zur Situation der Fachdidaktiken an der deutschen Hochschulen. Erziehungswissenschaft 18(35), 85-103 (also under www.fachdidaktik.org ).

Vollmer, H. J. (Org.) (2011). Fachdidaktik -European Perspectives? Symposium (Part $1+2)$ at the European Conference on Educational Research (ECER), Berlin, 13.-17.9.2011.

Vollmer, Helmut Johannes (2013). Didactique disciplinaire en Allemagne : développement et perspectives. In : Dorier, J.-L., Leutenegger, F. \& Schneuwly, B. (eds.), Didactique en construction - Constructions en didactique(s),(p. 39-62), coll. Raisons Educatives. Bruxelles : De Boeck. 